\title{
AC 2009-772: INCORPORATION OF GREEN PRINCIPLES INTO ORGANIC CHEMISTRY FOR ENGINEERS
}

Montserrat Rabago-Smith, Kettering Univeristy

Jennifer Aurandt, Kettering University 


\section{Incorporation of Green Principles into Organic Chemistry for Engineers}

Promoting environmentally responsible engineers and scientists necessitates the integration of green chemistry into the undergraduate engineering curriculum. In response to this need we have developed a pollution prevention (P2), Green Chemistry, and Green Engineering course designed for undergraduate engineering students that have taken general chemistry. Instead of the option of adding an additional course to a packed curriculum, we have modified a course that is required of all Mechanical and Industrial Engineering students at Kettering University--Chem 145: Industrial Organic Chemistry. The course would be a lab/lecture hybrid course entitled: "Green Industrial Organic Chemistry". This course would meet all of the learning objectives for the traditional organic chemistry course for engineers while using the 12 principles of Green Chemistry and Green Engineering as the spine of the course. Our pedagogy includes the engagement of students in interactive dialog, internet research on the web, networking opportunities with industry, government, and academic professionals that are knowledgeable and well experienced in the field of P2, the twelve principles of Green Chemistry and the principles of Green Engineering. In addition, laboratory exercises will be conducted in order to facilitate the learning of organic chemistry. The students' understanding of the learning objectives of organic chemistry will be assessed and compared to other sections taught without the incorporation of the green principles. Students' understanding of the green chemistry will also be assessed through both formative and summative assessment tools. The class will be assessed through peer review by the chemistry and engineering faculty. Development of this course is supported by Michigan Pollution Prevention Retired Engineers Technical Assistance Program (RETAP) Internship Program, administered by the Department of Environmental Quality, Environmental Science and Services Division.

\section{Introduction}

In a national workshop, Exploring Opportunities in Green Chemistry and Engineering Education: A workshop summary to the Chemical Sciences Roundtable, sponsored by the National Research Council, environmental leaders agreed that Green Chemistry must be incorporated into the undergraduate engineering curriculum. They proposed that an introductory Green Chemistry lecture/laboratory course is vital to future engineers and scientists. ${ }^{1}$ In support of this finding, we have developed and taught a course entitled "Green Industrial Organic Chemistry" to advance interests in chemical sciences and address the needs of educating undergraduate engineers/scientists in the principles of Green Chemistry.

Green Chemistry is defined by the Environmental Protection Agency as "the design of chemical products and processes that reduce or eliminate the use or generation of hazardous substances. Green chemistry applies across the life 
cycle, including the design, manufacture, and use of a chemical product". ${ }^{2}$ The 12 principles of Green Chemistry focus on reducing a chemical product's impact on the environment. The 12 principles are listed in Table $1 .^{3}$

\section{Table 1}

1.Prevent waste

2.Design safer chemicals and products

3.Design less hazardous chemical syntheses

4. Use renewable feed stocks

5.Use catalysts, not stoichiometric reagents

6. Avoid chemical derivatives

7. Maximize atom economy

8.Use safer solvents and reaction conditions

9.Increase energy efficiency

10. Design chemicals and products to degrade after use

11. Analyze in real time to prevent pollution

12. Minimize the potential for accidents

Green Chemistry focuses on the environmental impact of the lifecycle of a chemical product and it is appropriate to introduce this concept into an introductory organic chemistry class for engineers.

\section{Pedagogy}

Industrial Organic Chemistry is a three credit chemistry course with a total meeting time of 30 hours and is required for all Mechanical and Industrial Engineers. Kettering University has a unique curriculum in which students are in class for 11 weeks then participate in co-op for 11 weeks in alternating terms throughout the year. During the Winter and Spring terms, one section of this course is designed as "Green Industrial Organic Chemistry". The students are notified of the change in the content of the section through e-mails from the Registrar and after registering they are informed that they registered for the green section. The course will be divided into two modules which is team taught by two faculty members from the Chemistry and Biochemistry Department.

Green Industrial Organic Chemistry will have the same learning objectives, listed below, as the Industrial Organic Chemistry lecture that is presently offered. In modifying an existing course, it reduces the strain on an already packed curriculum, but still allows for the introduction of sustainability practices into the engineering curriculum. The course currently being offered and the next offering of the course is at the full enrollment of 48 students.

\section{The learning objectives for Green Industrial Organic Chemistry Course:}

Objective 1: Recognize the major functional groups present in organic compounds. 
Objective 2: Name the important classes of organic chemicals, including alkanes, alkenes, alkynes, aromatics, alcohols, amines, aldehydes, ketones and carboxylic acids.

Objective 3: Understand the general relationships between the structure of organic materials and their physical properties, including melting point, boiling point, and solubility.

Objective 4: Identify the important chemical reactions that organic materials undergo, including addition, elimination, substitution, oxidation and reduction.

Objective 5: Understand the origins and uses of important feedstock chemicals used for industrial syntheses of fuels, lubricants, consumer products and polymers.

Objective 6: Be familiar with chemical, physical and instrumental methods used to analyze and identify organic materials.

The pedagogy of each module will include a classroom component, laboratory exercise(s), and a networking opportunity as detailed below. The class is taught in an active learning style in which the students participate in the learning experience. The class uses the Brown and Poon's textbook, Introduction to Organic Chemistry, and handouts. ${ }^{4}$ For the laboratory component, the American Chemical Society Introduction to Green Chemistry is used. ${ }^{5}$

Module 1: Employing Green Organic Chemistry to Minimize Waste through the Lifecycle of the Product

The rationale behind the first module of the class is that in order to create the engineer of tomorrow, we must endow them with the skills and attitude needed to be environmentally conscious. Those skills, as outlined by the NRC workshop, include being sensitive to the environment, sensitive to human needs, having an environmental ethic, and having an understanding of natural systems. Teaching Green Chemistry and Engineering in coordination with pollution prevention will attain these goals.

In this section of the class, students will be taught the 12 principles of Green Chemistry through application of pollution prevention through the lifecycle of a product. In doing so, we will introduce organic chemistry compounds and physical properties. This module focuses on introducing students to organic chemicals, nomenclature, and reactions.

The students are introduced to organic compounds which are molecules that contain carbon, hydrogen, oxygen, and nitrogen. To give these atoms "life" we look at how these elements are cycled through the environment. When talking about the environment cycles, the chemistry of the conversion of the atoms to different forms is discussed. The class is then introduced to hydrocarbons. The application of burning alkanes to get energy is used to show the students combustion in a mixed atmosphere and the products that result. 
Nomenclature, which is often a tedious and dreaded topic in an organic chemistry class, is introduced using the active learning exercise of searching the Toxic Release Inventory (TRI) that is available from the EPA. ${ }^{6}$ The students choose a region and identify the organic compounds released in that area. They then draw line angle formulas and structural formulas for the compound, to reinforce the skills learned in class. Finally, they investigate why this compound is listed on the TRI. During this exercise the notion of halogens as contaminants is introduced.

Alkenes, alcohols and thiols are introduced by looking at their reactivity in the environment. The naming of the compounds is drawn again by the experience with the TRI exercise. Alkene reactions are introduced by looking at the reactivity of terpenes in the environment and using reference materials to show particulate formation upon reaction with ozone. ${ }^{6}$ This is used to excite the students about learning alkene reactions and mechanisms.

The students are then introduced to the carbonyl functional group by synthesizing biodiesel from renewable sources. They take a class period to synthesize biodiesel, then another is used to analyze it by Infrared Spectroscopy. This class puts "chemistry in the students' hands" and allows the students to realize that making fuel does not have to be dangerous.

In order to apply their knowledge and understand the materials that are being created by these chemicals, the students are introduced to the CES software. ${ }^{6}$ In this exercise, the students look at the environmental impact of materials and then look at the performance and function of the material to relate the chemistry that they have learned to products and engineering.

The learning objectives of the class that are achieved in this module include the recognition the major functional groups present in organic compounds through the TRI exercise. The students are able to name the important classes of organic chemicals, including: alkanes, alkenes, alkynes, alcohols, aldehydes, ketones and carboxylic acids through the TRI and CES activities. The students understand the general relationships between the structure of organic materials and their physical properties, including: melting point, boiling point, and solubility, through lecture materials. The students are able to identify the important chemical reactions that organic materials undergo, including: addition, oxidation and reduction. The comprehension of the learning objectives by the students is assessed as stated below.

\section{Module 2: Organic Pollutants and Pollution Prevention. Application of Green Chemistry in the Synthesis of Chemicals}

In the second module, students are introduced to various contaminants. These contaminants are separated into hydrocarbons, polymers, halogenated hydrocarbons (CFCs and HCFCs), dioxins, pesticides and detergents. By separating the contaminants into groups one can educate the students on their chemical properties and relate it to the effect in the environment. For example: bioaccumulation--the process of destruction of the ozone layer by CFCs, formation of dioxins, among others are demonstrated. In order to study polymers 
and their effect on the environment a CES software exercise is used. ${ }^{6}$ In this activity the students are given the names of three different polymers (cellulose acetate, ethylene vinyl alcohol and polybutylene) and they most write the angle line structure for the each of the monomers. Then, the students most answer a series of questions that relate to cost of the material, environmental information (i.e. $\mathrm{CO}_{2}$ foot print, biodegradable, etc.) and the chemical properties of the polymer. The Exxon Valdez spill is used as a case study to illustrate the environmental damage that pollution of hydrocarbonds cause. After students learn about different pollutants in the environment, they are introduced to the pollution prevention (P2) concept. To explain this concept, different applications of Green Chemistry are presented.

First, the 12 principles of Green Chemistry and the principles for Green Engineering are discussed. As an active learning experience, the students explore the application of such principles in their own co-op. This exercise has proved to be very insightful. The students' experience indicated that their co-op employers already use most of the Green Engineering principles in their processes. However, they believe that most of those practices are related to the reduction of manufacturing costs. A final analysis showed that most of the co-op companies perform regular recycling activities and prevention of waste. Also, most of the companies are mindful about the safety of their products and the impact on their communities. At the same time, the students explore the principles of Green Chemistry in their co-op. Students were surprised at how much Green Chemistry was applied at their companies. The Green Chemistry principle practiced most often is the use of safer materials in the production process. The students could remember and identify some of the harmful chemicals that were previously used by their companies, i.e. hexavalent chromium, PCBs, ethylene glycol.

To relate the Green Chemistry principles to the production of commonly used chemicals, the synthesis of the NAISD anti-inflammatory, ibuprofen, is demonstrated. The old synthesis of ibuprofen developed by Boots Company of England is a six-step process that produced large amounts of byproducts; this waste was mainly produced due to poor atom utilization. The "Green" synthesis of ibuprofen was developed by The BHC Company. This synthesis on the other hand, involves only three steps, and the atom utilization is much higher. Also, the use of HF in the "Green" synthesis was discussed. This example teaches the importance of atom economy, the use of shorter and efficient chemical reactions, as well as the safety of the chemicals used in the synthesis process. Then, the students are introduced to the concept of atom economy, reaction yield, and their relationship in the development of efficient and environmentally friendly synthesis. When talking about atom economy, the reactions covered in Module 1 and the reactions performed in their laboratories were reviewed. Thus, the students could reinforce previous knowledge while learning new material.

The use of new techniques like microwave and ultrasound are introduced and the synthesis of Methylenedioxyprecocene ${ }^{9}$ serve as an example of a solvent-less synthesis that utilizes microwaves to increase the rate of the reaction. The use of new techniques in the synthesis of organic molecules 
served as a good example of how engineers can design instrumentation that aids chemists in the preparation of novel organic molecules and the processes used to prepare them. Also, we introduce the use of supercritical fluid carbon dioxide instead perchloroethylene (PERC) in the dry cleaning industry. This serves as a feasible example of the impact of the overall decrease in the production of pollutants. Finally, the students perform the synthesis of biodiesel. This synthesis exemplifies the importance of using alternative fuels that are produced from renewable feedstocks.

The learning objectives of the class that are achieved in this module include understanding the relationships between the structure of organic materials and their physical properties through learning about octane ratings and fractional distillation of petroleum. Students are able to identify the important chemical reactions that organic materials undergo, including the formation of various polymers. The students are able to understand the origins and uses of important feedstock chemicals used for industrial syntheses of fuels, lubricants, consumer products, and polymers, and are familiar with chemical, physical, and instrumental methods used to analyze and identify organic materials through the biodiesel exercise.

\section{Assessment}

The plan for assessment is presented below. (The class is currently being conducted so the results of the assessment will be presented at the meeting. We have documented the results from the assessment tools used thus far). The assessment of student learning was performed by using a summative assessment with a multiple choice test at the beginning to assess the prior level of knowledge, and a post test at the end of class to determine the level of knowledge obtained. The assessment test was given to all sections of the Industrial Organic Chemistry class, including those without the "green" principles incorporated. The results of the assessment will be compared in order to determine the amount of material retained by the section that is taught using Green principles, versus those that do not. Each question in the assessment test is mapped to the learning objective(s) for the course.

In addition, the students take a perception of knowledge questionnaire that assesses how much they feel that they know about the topics covered in the class. They are given the knowledge questionnaire at the beginning and end of the term through Blackboard, the course management tool. The phrasing of these questions are as follows:

Mark your level of knowledge of the listed subject areas.

1) Able to recognize the major functional groups present

in organic compounds.

Not at all

Somewhat

Capable 
Very

Capable

The assessment of teaching and of class content has been performed through both summative and formative assessment. The class is assessed every two weeks using the SII system of assessment. This technique requires the students to write down two strengths for the class, an area for improvement, and an insight for the class. Thus far, the strengths of the class as stated by the students in the SIl exercise have been as follows: "The green spin actually makes chemistry slightly more interesting", "... will be benefit in our careers", and "Very open feeling and enthusiastic- I want to learn more". The assessment also states that they like that two professors are teaching the class, and that they use well laid out slides.

The improvements for the class would be to provide easier quizzes to the students (quizzes are given everyday). The insights that have been reported by the students are: "How what we can do can affect the environment (IE your example of Toledo's wastewater), how we should be more careful with what we do", "I did not realize that the toxic chemicals could be fixed by really re-thinking the chemical composition and the way it is bonded", "I did not realize that some medicines, such as aspirin contain certain molecules that are not good for the environment", "How carbon and Biology cross", and "Effects of chemicals on the environment". Many stated that they actually "get" topics now, that they should have learned in general chemistry. Every class period, the faculty that team teach the class assess each class using the SII system of assessment. This aids in development of class materials and ensures that the class will cover all learning objectives to ensure that the students are learning.

\section{Evaluation Plan}

The students are evaluated using two tests, one for each module, and a cumulative final. A portion of the final will be the assessment test. In addition, they have a quiz every day, and a participation and homework grade. Thus far, all students are passing the course and the average is around $80 \%$.

\section{Conclusions}

Integrating green chemistry principles and the environment into an introductory chemistry course increases the interest of the student in chemistry. The class that has developed offers a resource for incorporation of the lifecycle concept of sustainability into an engineering curriculum without the addition of more courses.

Many of the students have taken the course because "because it fit their schedule" and it was a required course. Therefore, we had many skeptics when we started. However, many of the SIl comments from the students have demonstrated that this class makes chemistry more "real" and applicable to everyday life. Focusing on the environment has increased their interest in chemistry. Students have consistently commented that they like the teaching 
style that is used in the classroom and the atmosphere that encourages discussion on these topics.

A challenge that has presented itself while teaching the course is that some material has to be cut out or less time must be spent on it because of the extra material added. With that being said, the students seem to retain more of the material because of the applications that are presented in the class. In addition, there is not enough time to present many examples, but we have found that worksheets that apply their knowledge and extra review sessions have been helpful. In addition, there are areas where the course will be modified due to assessment results. Worksheets will be given for every topic.

\section{References}

1. "Exploring Opportunities in Green Chemistry and Engineering Education: A Workshop Summary to the Chemical Sciences Roundtable" sponsored by the National Research Council on November 7, 2005.

2. "EPA" http://www.epa.gov/greenchemistry/pubs/about gc.html (Accessed March 17,2009)

3. Anastas, Paul and Warner, John, Green Chemistry: Theory and Practice. Oxford University Press, 1998.

4. Brown and Poon, Introduction to Organic Chemistry, Third Edition, Wiley 2005.

5. Introduction to Green Chemistry, American Chemical Society, 2002.

6. "Toxic Release Inventory" http://www.epa.gov/tri/ (accessed March 17, 2009)

7. Nøjgaarda, JK, Bildeb, M, Stenbyc, C, Nielsenb, OJ, and Wolkoffaalndoor, $\mathrm{P}$, The effect of nitrogen dioxide on particle formation during ozonolysis of two abundant monoterpenes indoors. Atmospheric Environment 40 (2006) 1030-1042.

8. "Granta Design" http://www.grantadesign.com/education/ (accessed March 17, 2009)

9. Dintzner, MR* Wucka, PR and Lyons, TW, Microwave-Assisted Synthesis of a Natural Insecticide on Basic Montmorillonite K10 Clay. Journal of Chemical Education 83, 2 (2006) 270-272.

\section{Acknowledgements}

This class is funded by the Michigan DEQ RETAP Internship Program Environment Science and Service Division. 